\title{
The Leech Homeobox Gene Lox4 May Determine Segmental Differentiation of Identified Neurons
}

\author{
Victoria Y. Wong, Gabriel O. Aisemberg, Wen-Biao Gan, and Eduardo R. Macagno \\ Department of Biological Sciences, Columbia University, New York, New York 10027
}

\begin{abstract}
We cloned and characterized a new leech homeobox gene, Lox4, a homolog of the Drosophila genes Ultrabithorax and abdominal-A. Lox4 has a complex and dynamic pattern of expression within a series of segmentally homologous neurons. These include a pair of specialized motor neurons of one segmental ganglion, the rostral penile evertors (RPEs), and their segmental homologs in other midbody ganglia. During gangliogenesis, Lox4 was expressed within this series of neurons in three different temporal patterns: (1) it was never expressed in the RPE homologs of ganglia 1-3; (2) it was expressed in the RPEs during gangliogenesis, but was turned off when these neurons started to differentiate after gangliogenesis; and (3) it was expressed in the RPE homologs of segments 4-5 and 7-21 during gangliogenesis and the subsequent period of axonogenesis. We found that these neurons have three distinct peripheral axonal morphologies that correlate with the three temporal patterns of expression. Our results suggest that the homeobox gene Lox4 may determine neuronal identities within this series of segmental homologs.

[Key words: neuron, axon, homeodomain, Hirudo medicinalis, Hox genes, CNS, morphology]
\end{abstract}

There is more cellular diversity within the nervous system than in any other system in an animal. Although essential for understanding nervous system development and pathology, the mechanisms that generate this diversity are extremely complex and, as a consequence, poorly understood. A useful model for addressing some basic aspects of this issue is the regional differentiation in invertebrates of segmentally repeated neurons. These neurons derive from precursors located in similar cellular environments, but nevertheless acquire unique identities. Although both cell-cell interactions and autonomous factors appear to contribute to their different developmental fates, the specific influence of the environment on neuronal identity depends largely on the intrinsic properties of an individual cell. To gain a better understanding of the function of autonomous factors in neuronal differentiation, a fruitful approach has been to examine the ex-

\footnotetext{
Received Feb. 16, 1995; revised Apr. 14, 1995; accepted Apr. 20, 1995

We thank Laura Wolszon for her critical reading of the manuscript, Tim Gershon for removing the male organ from experimental embryos, Mike Nitabach for immunizing the rabbits and for helpful discussions, and Nik Necles for photographic work. We also thank Marty Shankland for his help with the initial in situ hybridization experiments and Anne Duggan for useful comments on an earlier version of the manuscript. Lastly, we thank J.-L. Picard and K. Janeway. This work was supported by NIH Grant HD-20954.

Correspondence should be addressed to Gabriel $\mathrm{O}$. Aisemberg at the above address.
}

Copyright (C) 1995 Society for Neuroscience $0270-6474 / 95 / 155551-09 \$ 05.00 / 0$ pression and function of regulatory proteins involved in controlling early development in the nervous system.

The leech Hirudo medicinalis provides a uniquely advantageous system to study these problems at the level of single, identified neurons. Leeches have a simple CNS comprising a ventral nerve cord with 32 segmental neuromeres and a supraesophageal ganglion of nonsegmental origin. Four neuromeres fuse to form the head ganglion and seven to form the tail ganglion. The remaining 21 neuromeres form the midbody ganglia, which have about 400 neurons each (Macagno, 1980). Many of these neurons can be reliably identified in the embryo and are amenable to experimental manipulation at early developmental stages. They differentiate in very similar early embryonic environments, yet many segmentally homologous neurons exhibit distinct, segment-specific patterns of differentiation (Glover and Mason, 1986; Gao and Macagno, 1987a,b; Jellies et al., 1987; Stewart et al., 1991; Jellies et al., 1992; reviewed in French and Kristan, 1994). Although a role for cell-cell interactions during development has been demonstrated for some of these neurons, it is likely that certain fates and pathways of differentiation are initially determined by specific, cell-autonomous factors that in turn bias the responses to environmental signals.

The Hox/HOM genes and other related homeobox-containing genes code for transcription factors which are highly conserved among a wide variety of species (reviewed in Kappen and Ruddle, 1993; Krumlauf, 1994). In addition to their early function in determining anteroposterior (A-P) positional information, the Hox/HOM genes are later expressed at high levels in the nervous system (reviewed in Doe and Scott, 1988; Kessel and Gruss, 1990; Boncinelli et al., 1993), where they are likely to be involved in the determination of neuronal identities.

Previous work in this laboratory has determined that leech Hox/ HOM genes are expressed in segmentally repeated subsets of neurons within their particular A-P domains (Wysocka-Diller et al., 1989; Aisemberg et al., 1993, 1995; Aisemberg and Macagno, 1994). We present here the characterization of Lox4, a leech Hox/ HOM gene that displays a complex and dynamic pattern of expression in the CNS and offers a very interesting model for the study of differentiation within a series of segmentally homologous neurons. The results we present here suggest that Lox4 plays a key role in the specification of three different cell fates among at least one group of segmentally homologous neurons.

\section{Materials and Methods}

Animals. Embryos obtained from our colony of Hirudo medicinalis were maintained at $23^{\circ} \mathrm{C}$ within their coconns until embryonic day 8 (E8), and in sterile artificial spring water $(0.5 \mathrm{gm} / \mathrm{liter}$ Instant Ocean, Aquarium Systems, Sarrebourg, France) afterwards. Under these conditions, embryonic development is completed in about $30 \mathrm{~d}$.

Cloning and sequencing. The Lox4 homeobox was isolated by PCR 
amplification from genomic DNA. A reaction mixture of $100 \mu \mathrm{l}$ contained $10 \mathrm{~mm}$ Tris-IICl, pII $8.3,50 \mathrm{mM} \mathrm{KCl}, 3 \mathrm{mM} \mathrm{MgCl}_{2}, 200 \mu \mathrm{M}$ dGTP, $200 \mu \mathrm{M}$ dCTP, $200 \mu \mathrm{M}$ dATP, $200 \mu \mathrm{M}$ dTTP, $0.8 \mu \mathrm{g}$ of each oligonucleotide primer, $5 \mu \mathrm{g}$ of leech DNA, and $2.5 \mathrm{U}$ of Taq DNA polymerase (Perkin-Elmer Cetus, Norwalk, CT). After $1 \mathrm{~min}$ at $94^{\circ} \mathrm{C}$, the sample was subjected to 10 cycles of $94^{\circ} \mathrm{C}, 35^{\circ} \mathrm{C}$, and $72^{\circ} \mathrm{C}(1 \mathrm{~min}$ at each temperature), followed by 25 cycles in which the annealing temperature was increased from $35^{\circ} \mathrm{C}$ to $50^{\circ} \mathrm{C}$, and a final 5 min extension at $72^{\circ} \mathrm{C}$. The sequences of the primers were GAA/GC/TTGGAA/ GAAA/GGAA/GTT for the 5' primer and CT/GCCT/GG/ATTT/CTGG/ AAACCA for the $3^{\prime}$ primer. The amplified homeobox fragments of 120 bp were cloned into the vector pIBI31 (International Biotechnologies, Inc., New Haven, CT). Individual clones were sequenced with the Sequenase kit (U.S. Biochemicals, Cleveland, $\mathrm{OH}$ ).

The Lox4 fragment was used as a probe to screen, at high stringency, a $\lambda$ Zap (Stratagenc, La Jolla, CA) cDNA library of late Hirudo cmbryos (a generous gift of Dr. James Boulter, The Salk Institute). Two positive clones were isolated from about $1 \times 10^{6}$ plaques. They were plaquepurified and excised in vivo according to the manufacturer's instructions, and found to contain inserts of 2.4 and $1.7 \mathrm{~kb}$. A series of nested deletions of the longest Lox4 cDNA clone were generated using the Erasea-Base system (Promega, Madison, WI) and both strands of this Lox4 cDNA clone were sequenced.

RNA analysis. PolyA ${ }^{+}$RNA was purified by oligo(dT)-cellulose chromatography from juvenile (10-30 d after hatching) and embryonic (E10-E13) leeches, separated in an agarose gel containing formaldehyde (about $5 \mu \mathrm{g}$ of polyA ${ }^{+}$RNA per lane), transferred onto a nylon membrane, and hybridized at high stringency to a ${ }^{32} \mathrm{P}$-labeled antisense riboprobe synthesized from the $2.4 \mathrm{~kb}$ Lox 4 cDNA clone, as described in Aisemberg and Macagno (1994). For in situ hybridization, a digoxigenin-labeled Lox4 riboprobe was used to probe whole Hirudo embryos under essentially the same conditions as described in Nardelli-Haefliger and Shankland (1992).

Generation of a Lox 4 antibody and antibody staining of embryos. A fragment containing the entire Lox4 open reading frame was amplified using PCR and subcloned into the BamHI site located upstream of the glutathione S-transferase gene (GST) in the pGEX-2T vector (Smith and Johnson, 1988). The recombinant plasmid was transformed into $E$. coli. IPTG induction of the Lox4-GST fusion protein and glutathioneagarose purification were performed as described in Ausubel et al (1987). The purified Lox4-GST fusion protein was used to immunize three adult male rabbits and the antisera generated by the rabbits were affinity-purified with chromatography units containing covalently bound Lox4-GST as described in $\Lambda$ isemberg and Macagno (1994).

In order to eliminate potentially undesirable binding activities, the purified antibodies were sequentially adsorbed with GST, two other $\mathrm{Hi}$ rudo homeodomain proteins, Loxl and Lox3 (Aisemberg and Macagno, 1994; J. W. Wysocka-Diller, G. O. Aisemberg, and E. R. Macagno, unpublished observations), and total protein from leech embryos. Two of the antisera produced identical staining patterns and one of them was used for the results presented here. Embryos were stained with this antibody as previously described (Aisemberg and Macagno, 1994). For each preparation, a series of optical sections were recorded and superimposed in a single image using a Zeiss Axioplan microscope coupled to a Bio-Rad MRC-600 laser-scanning confocal system.

Intracellular injection of dyes. For double-labeling, identified neurons of live, dissected embryos were injected with Lucifer yellow using a procedure described in Gao and Macagno (1987a). After 20-30 min, the embryos were fixed and stained with the Lox4 antibody. In other experiments, the embryos were fixed and the neurons were labeled with DiI, as described in Gan and Macagno (1995).

\section{Results}

Lox4 is an Ultrabithorax/abdominal-A homolog

A 120 bp Lox4 fragment was initially amplified and cloned from genomic DNA using degenerate homeobox-specific primers. Subsequently, two Lox4 cDNA clones were obtained from a late embryonic cDNA library screened with this PCR fragment. The longest cDNA clone was chosen for further characterization (Fig. 1). This cDN $\Lambda$ contained a long open reading frame (nucleotides 260-943) that coded for a 228 amino acid homeodomain protein (Fig. $1 A$ ). In-frame stop codons at positions 101 and 140 preceded a methionine codon at position
260. A probe derived from this cDNA clone, which was assumed to contain the entire coding region of Lox4, detected a transcript of about $3.4 \mathrm{~kb}$ in both E10-E13 embryos and juvenile leeches (Fig. 1B).

The Lox4 protein contained an Antennapedia- (Antp-) class homeodomain (for review, see Bürglin, 1993). The recognition helix (helix 3) of Lox4 was identical to the one of Antp-class homeodomains (Fig. 1C). In addition, Lox4 contained a YPWM motif that is found upstream of the homeodomain in most Antpclass genes (McGinnis and Krumlauf, 1992). The highest degree of homeodomain homology to Lox4 occurred in Hox genes of groups 6 and 7 (Scott, 1992), with a 52-53/60 amino acid identity.

The Lox4 homeobox also showed high homology to the homeoboxes of leech Lox2 (Wysocka-Diller et al., 1989), and Drosophila Ultrabithorax (Ubx; Kornfeld et al., 1988) and abdominal-A (abd-A; Karch et al., 1990), with 52/60, 51/60, and 52/60 amino acid identities, respectively. The homology of Lox4 to $L o x 2, U b x$, and $a b d-A$ was found to extend to a sequence adjacent to the $\mathrm{C}$-cnd of the homeodomain (Fig. 1C). This previously described conserved motif (Wysocka-Diller et al., 1989) has not been found in any other arthropod or leech homeobox genes. Within this 8-amino acid-long region, Lox4 had seven amino acid identities to $U b x$, and four to $a b d-A$. This high degree of similarity in and downstream from the homeodomain suggests that Lox2 and Lox4 are leech homologs of the arthropod genes $U b x$ and $a b d-A$.

Lox2 and Lox4 shared additional homology within the upstream region adjacent to the homeodomain (about 50\% homology within a 20 amino acid stretch). Lox4 homology to $U b x$ and $a b d-A$ was mostly limited to the YPWM sequence in this region. Lox4 was also more homologous to Lox2 within the downstream region adjacent to the homeodomain (over $50 \%$ homology within a 20 amino acid stretch). A computer-generated comparison of the putative evolutionary distances between these sequences showed that leech and arthropod genes form two completely separated groups (Fig. 1D). These results suggest that the gene duplications that produced $U b \times / a b d-A$ and Lox2/Lox4 occurred independently in arthropods and annelids.

\section{Lox4 is expressed in a subset of iterated central neurons}

The expression pattern of Lox4 was determined in whole embryos by in situ hybridization and antibody staining. Virtually identical results were obtained with these two assays of gene expression, though antibody staining was more sensitive.

The earliest detection of Lox4 transcription was at embryonic day 6 (E6), in discrete bilateral patches starting at about midbody segment 10 (M10) (Fig. 2A). Although the ganglia were not yet formed in these segments, the Lox4-positive regions are known to contain precursors of central neurons (Fernández and Stent, 1992).

At E9 (Fig. 2B,C), after the end of gangliogenesis, the Lox4 mRNA and protein were primarily detected in the CNS, with the majority of expressing neurons being in midbody ganglion 10 (MG10) to MG21. Most of these neurons were found in the posterior half of each ganglion. The anterior boundary of Lox4 expression in the CNS was found to be in MG3, where only two neurons, located at the center of the ganglion, expressed Lox4 (see high-magnification image of Fig. 3I,J). There was also expression in peripheral tissues in segments M13 to M21.

At E13 (Fig. 2D), when the level of Lox4 expression appeared to be the highest, we could count about 100 Lox4-positive neu- 


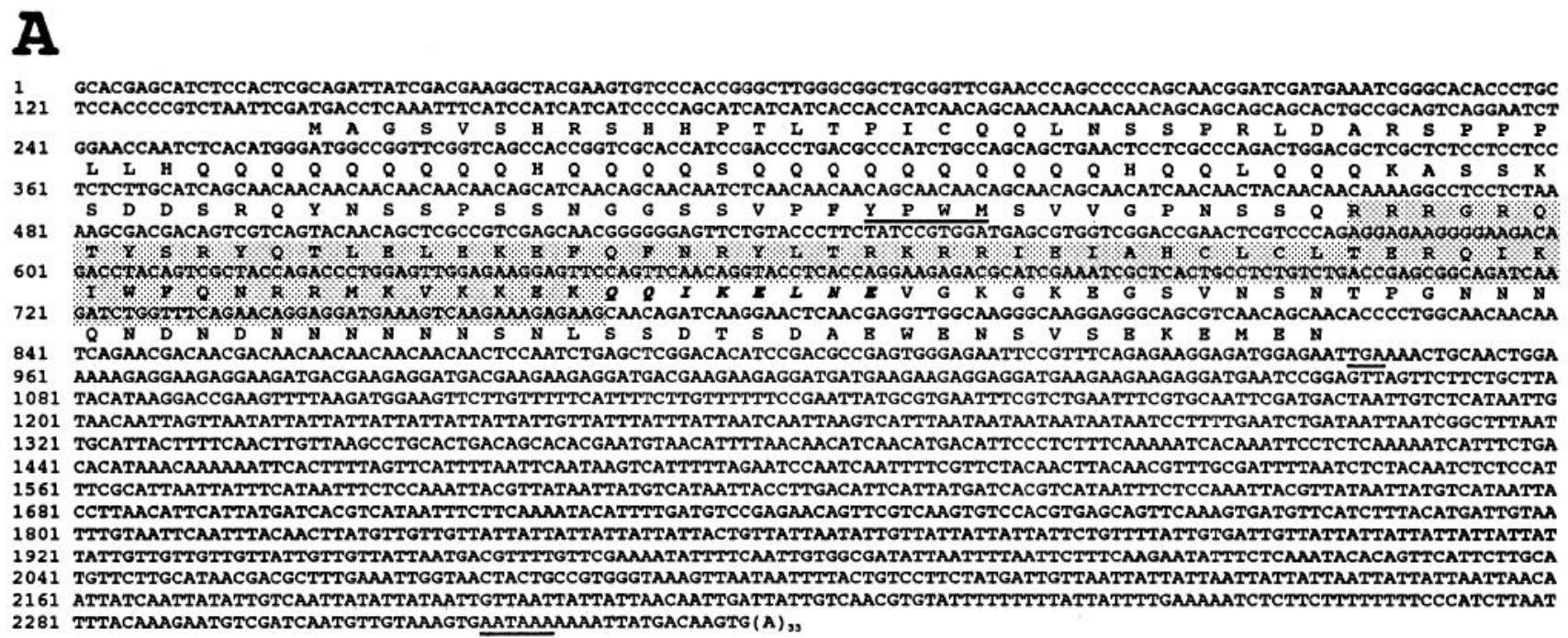

B
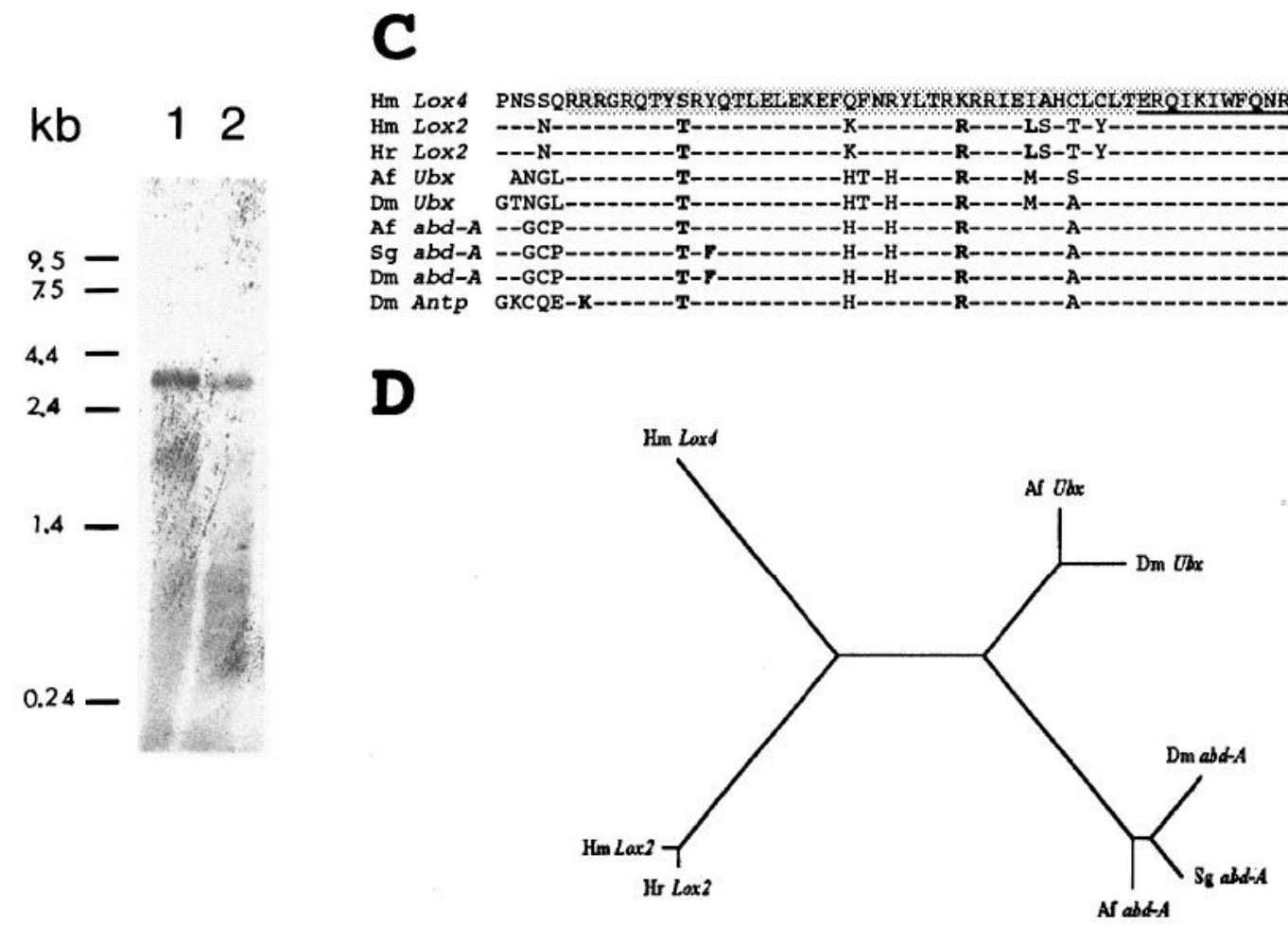

Figure 1. Structure of Lox4. A, Nucleotide and deduced amino acid sequence of the Lox4 cDNA. The YPWM motif, the stop codon at the end of the coding region and the polyadenylation site are underlined. In $A$ and $C$, the homeodomain is shaded and the region immediately downstream that is conserved between Lox2/Lox4, and Ubx/abd-A is indicated with bold italics. B, Detection of the Lox4 mRNA on a Northern blot of embryonic (lane 1 ) and juvenile (lane 2) leeches hybridized to a cDNA probe. The positions of molecular weight markers (in kb) are indicated. $C$, Sequence homology between the homeodomain regions of Lox4 and other $U b x / a b d$-A-like genes from leeches and arthropods. From leeches, three genes are compared: Helobdella robusta (Hr) Lox2 (Nardelli-Haefliger and Shankland, 1992), and Hirudo medicinalis (Hm) Lox2 (Wysocka-Diller et al., 1989) and Lox4 (this article). From arthropods, six genes available from three major groups are included: the brine shrimp Artemia franciscana (Af) Ubx and abd-A (Averof and Akam, 1993), the locust Schistocerca gregaria $(\mathrm{Sg})$ abd-A (Tear et al., 1990), and the Drosophila melanogaster (Dm) Antp (Schneuwly et al., 1986), Ubx (Kornfeld et al., 1989) and abd-A (Karch et al., 1990). The helix 3 is underlined. The dashes represent amino acid identities and the bold letters conservative changes. $D$, An evolutionary tree deduced from the $U b x / a b d-A$-like sequences compared in $C$ was obtained using the MSA program (Lipman et al., 1989). The fact that leech and arthropod genes appear completely segregated in this diagram suggests that the gene duplications that produced $U b x$ and $a b d-A$ in arthropods, and Lox2 and Lox4 in leeches, happened independently in the two lineages.

rons per ganglion in MG13 to MG21. After E15, Lox4 expression was detectable in fewer neurons (data not shown). This could be due to downregulation of Lox4, which showed a weaker signal in juvenile leeches than in embryos on Northern blots (Fig. $1 B)$.

\section{Lox4 is expressed transiently in the RPE neurons of MG6}

We found that a segmentally repeated series of paired neurons located at the anterior margins of all midbody ganglia displayed differential expression of Lox 4 during early embryogenesis. We identified these neurons as the RPEs (rostral penile 

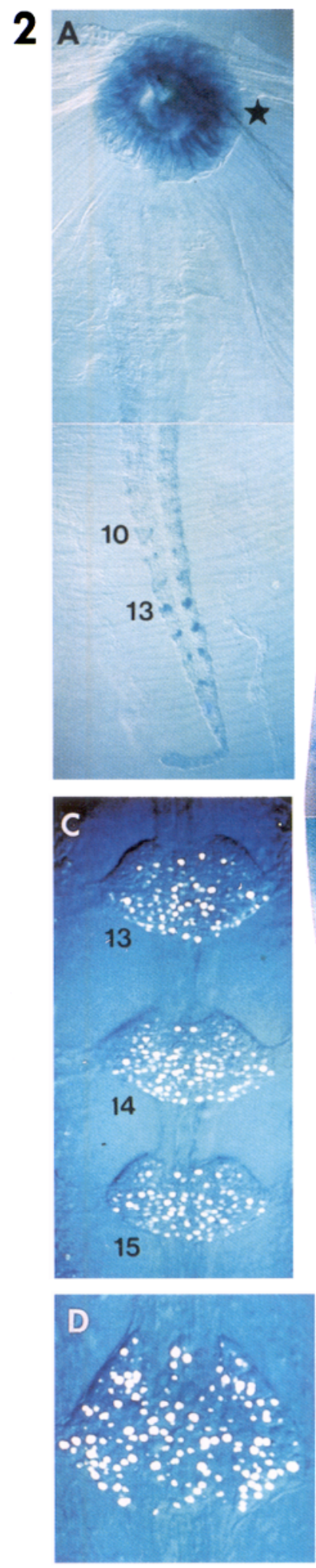
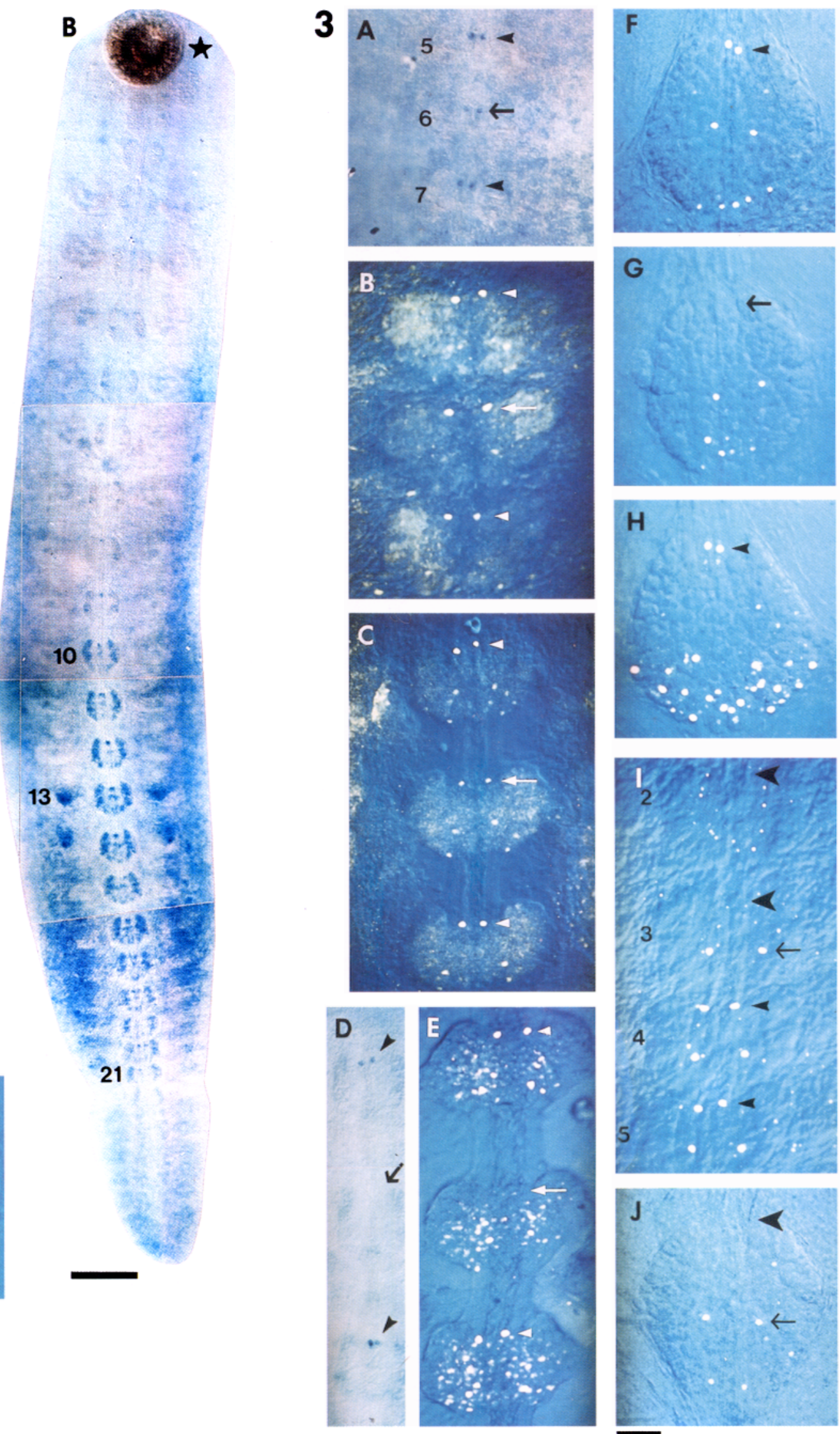

Figure 2. Lox4 expression in embryos. $A$ and $B$ are Nomarski images of Lox 4 in situ hybridizations. $C$ and $D$ are projections of serial optical sections of Lox 4 antibody stainings, superimposed with transmitted light images of the same fields. The numbers in $A-C$ identify midbody ganglia. $A$, The earliest transcription was detected at E6, beginning at segment M10. The strongest signal was in M13-M21. The staining on the embryonic 
evertor neurons) in MG6 and as their putative homologs in all other midbody ganglia, which we named RMVs (rostralmost ventral neurons).

The RPEs are a single pair of motor neurons found only in MG6. They are located on the ventral aspect, close to the midline, and are the most anterior neurons in the ganglion. These neurons are known to control penile eversion in adult hirudinid leeches (Zipser, 1979), and they innervate the male organ selectively during embryogenesis (Baptista and Macagno, 1988). In contrast, back-fills obtained by placing dye in the male organ indicate that the RMVs in adjacent ganglia do not innervate the male organ (Becker et al., 1995). There is only one pair of RMVs per segment, and they occupy the same position in the ganglion as the RPEs.

The Lox4 mRNA and protein were initially detected at E7, in the RPEs of MG6 and in the RMVs of MG4-MG5 and MG7MG21 (Fig. 3A,B). These RMV cells are henceforth designated as Lox4-positive RMVs (pRMVs). At E8, Lox4 expression began to decrease in the RPEs, but not in the pRMVs (Fig. 3C). By E9, the Lox4 mRNA and protein were not detectable in the RPEs whereas the pRMVs continued to express Lox4 at about the same levels as earlier (Fig. 3D,E). The expression pattern of Lox4 in RPEs and pRMVs remained unchanged at later stages (at least between E9 and E13; see Fig. $3 F-H$ ). In contrast, the RMVs of MG1-MG3 (henceforth referred to as the Lox4-negative RMVs or nRMVs) did not express detectable levels of Lox4 mRNA (not shown) or protein (Fig. 3I,J) at any age examined (E7-E13). Thus, there were three distinct time courses of Lox4 expression within this series of segmentally repeated neurons: (1) the nRMVs of MG1-MG3 never expressed Lox4, (2) the RPEs of MG6 expressed Lox4 transiently (only from E7 to E8), and (3) the pRMVs of MG4-MG5 and MG7-MG21 expressed Lox4 continuously between E7 and E13, and perhaps later (illustrated in Fig. 5).

Since the phenotype of at least one other neuron, the Retzius cell, is known to be affected by contacting the male organ (reviewed in French and Kristan, 1994), we considered the possibility that the change in Lox4 expression in the RPEs might also be caused by an inductive effect of the developing male organ. To test this hypothesis, the male organ primordium was removed from six early E8 embryos, before the RPE projections reach this tissue, and then examined the expression of Lox4 at E9. However, all operated embryos were unaffected and showed the same temporal pattern of expression as normal embryos: their RPEs had no detectable Lox4 protein at E9 (data not shown).
Table 1. Number of neurons of the RPE-RMV series of segmental homologs whose axonal morphology was examined

\begin{tabular}{lcccllll} 
& \multicolumn{3}{l}{ Neurons filled with LY } & & \multicolumn{3}{c}{ Neurons filled with DiI } \\
\cline { 2 - 4 } \cline { 6 - 7 } Stage & RPEs & nRMVs $^{a}$ & $\mathrm{pRMVs}^{b}$ & & RPEs & nRMVs $^{a}$ & $\mathrm{pRMVs}^{b}$ \\
\hline E8-E9 & 17 & 10 & 27 & 6 & 12 & 13 \\
E12-E13 & 2 & 1 & 11 & 9 & 15 & 26 \\
\hline
\end{tabular}

a The nRMVs of segments M2 and M3 were examined.

${ }^{b}$ The pRMVs of segments M4, M5, M7, and M8 were examined.

\section{RPEs and RMVs have divergent axonal morphologies that correlate with differences in Lox4 expression}

Seeking evidence that Lox4 might be involved in the determination of neuronal identities, we examined the morphology of the RPEs and RMVs at times when their expression of Lox4 differed. We first determined whether these cells could be accurately identified and filled with dye. Presumed RPEs and RMVs were first injected with the fluorescent dye Lucifer yellow (LY), and then stained with the Lox4 antibody to confirm their identities. We thereby filled successfully a total of 68 RPEs and RMVs in MG2-MG13 (Table 1). The double stainings consistently showed that these neurons have very similar arbors within the ganglionic neuropil, before their projections exit contralaterally through the anterior nerve root. Other neurons with somata close to those of the RPEs and the RMVs that were intentionally injected with dye revealed very different projection patterns (data not shown).

To examine the peripheral axonal morphology in greater detail than is possible with LY, we injected the lipophilic dye DiI into the RPEs and RMVs in MG2-MG8 (Fig. 4). A total of 81 cells were filled (Table 1). At E9, a branch of the peripheral projection of the RPEs begins to grow along the sex nerve toward the primordium of the male organ (Baptista and Macagno, 1988). This is the time when Lox4 expression became undetectable in the RPEs. By E12, this branch reaches and innervates the male organ (as in Fig. 4A), whereas all the remaining branches are retracting (Baptista and Macagno, 1988).

In contrast, the Lox4-positive pRMVs displayed a peripheral growth pattern strikingly different from that of the RPEs (Fig. $4 B, C$ ). At E9, the primary projection of these pRMVs was longer than that of the RPEs, extending laterally into peripheral tissues of the body wall. In addition, this projection started to extend two pairs of major longitudinal branches (not shown). The differences in the peripheral growth pattern be-

\section{$\leftarrow$}

mouth in $A$ and $B$ (stars) was nonspecific. B, At E9, the strongest Lox4 expression was in the CNS, from MG10 to MG21, as well as in the periphery, from M13 to M21. C, At E10, the Lox4 protein was detected in an iterated subset of neurons of the posterior CNS. $D$, At E13, about 100 neurons per ganglion were Lox4-positive from MG13 to MG21. This number decreased by E15. Scale bar: $A$ and $B, 250 \mu \mathrm{m} ; C$ and $D, 80$ $\mu \mathrm{m}$. Anterior is up in all the panels.

Figure 3. Lox4 expression in RPEs and RMVs. $A$ and $D$ are Nomarski images of Lox4 in situ hybridizations. $B, C$, and $E-J$ are projections of serial optical sections of Lox4 antibody stainings, superimposed with transmitted light images of the same fields. $A-E$ show the temporal pattern of Lox4 expression in MG5-MG7 during gangliogenesis. In all the panels of this figure, the small arrowheads indicate Lox4-positive pRMVs. In $A-E$ and $G$ the arrows indicate the RPEs of MG6. $A$ and $B$, Early in gangliogenesis (E7), the Lox4 mRNA and protein were detected in RPEs and pRMVs of MG5-MG7. The numbers in $A$ indicate the segmental positions of these ganglia. $C$, A day later (E8), there was a lower level of expression of Lox4 in the RPEs than in the pRMVs of MG5 and MG7. $D$ and $E$, At the end of gangliogenesis (E9), Lox4 was undetectable in the RPEs but maintained approximately constant levels in the pRMVs of MG5 and MG7. $F-H$, At E13, when axonal growth into the periphery is still in progress, the Lox4 expression pattern established at the end of gangliogenesis was unchanged in MG5 $(F)$, MG6 $(G)$, and MG7 $(H)$. $I$ and $J$, The nRMVs, anterior to MG4 (large arrowhead), never expressed Lox4. The anterior boundary of Lox4 was found to be in MG3, in a central pair of neurons (arrows), first detected at E7 $(I)$ and were still present at E13 $(J)$. The numbers in $I$ identify MG2-MG5. Scale bar: $A, 70 \mu \mathrm{m} ; B, 35 \mu \mathrm{m} ; C, 45$ $\mu \mathrm{m} ; D, 90 \mu \mathrm{m} ; E, 30 \mu \mathrm{m} ; F$ and $G, 50 \mu \mathrm{m}$. Anterior is up in all the panels. 
Figure 4. Axonal morphologies of RPE and RMV neurons. All panels show projections of serial optical sections of RPEs, nRMVs, and pRMVs that were filled with DiI in dissected, fixed E13 embryos. The approximate positions of the cell bodies are indicated with arrowheads. In $A, D$, and $E$, some dye diffused into other regions of the ganglion as well, but did not label the axons of any other neurons. $A$, An RPE of MG6. The branches that arborize over the male organ are indicated by an arrow. B, A pRMV of MG5. $C$, A pRMV of MG4 (the cell body and ganglion are out of the field of view). $D$, An nRMV of MG2. A branch that reaches the midline is indicated with an arrow. E, An nRMV of MG3. Note that the nRMVs have shorter, irregular longitudinal branches that are associated with a larger number of fine processes than the pRMV branches. An asterisk indicates a part of the longitudinal connective nerve. Scale bar, $100 \mu \mathrm{m}$. Anterior is up in all the panels.

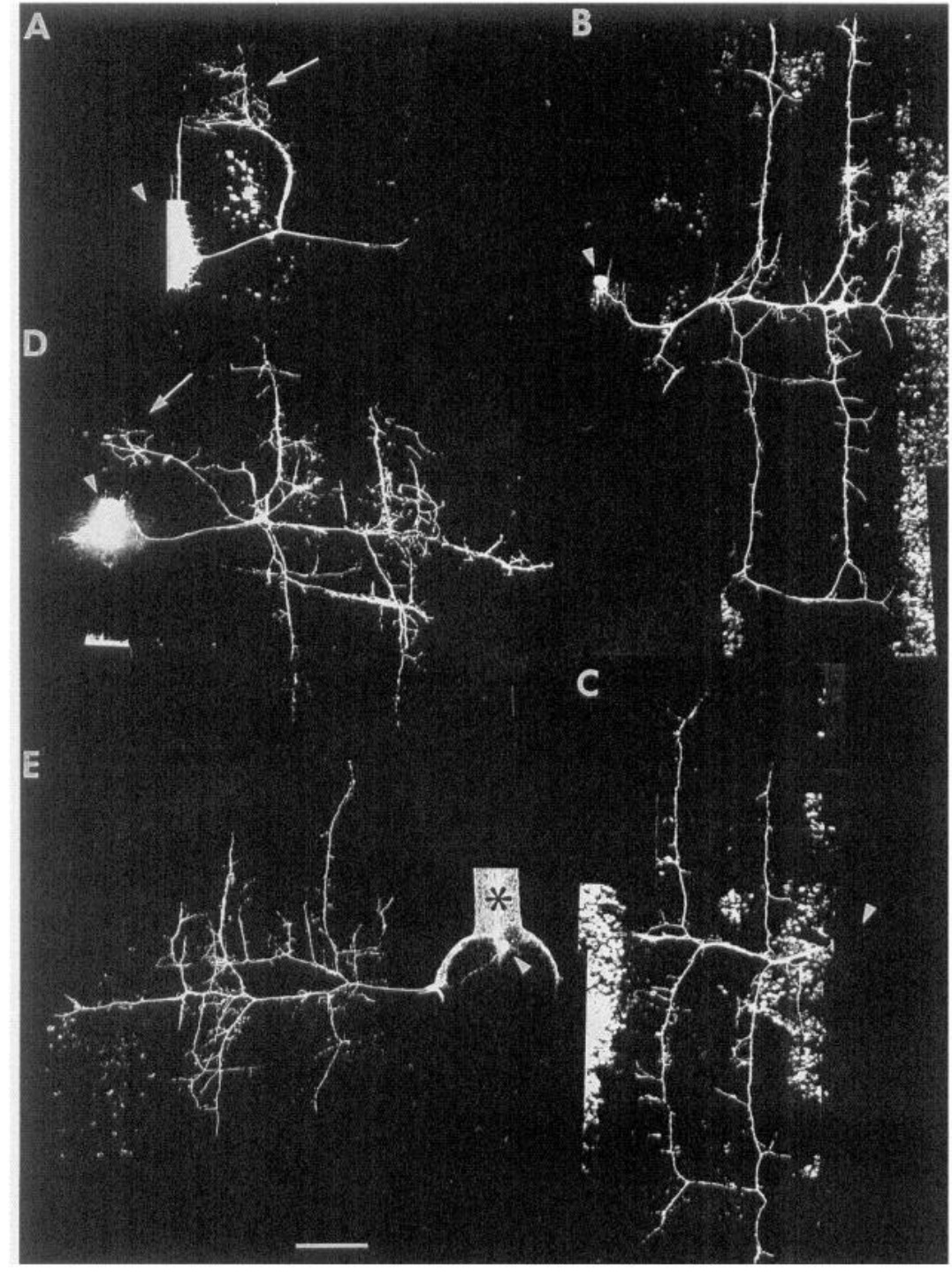

came even more evident by E12 (Fig. $4 B, C$ ), when the longitudinal branches of the pRMVs grew further along the A-P axis of the body wall, extending for approximately 2 body segments.

The Lox4-negative nRMVs of MG2 and MG3 showed a third, distinct axonal morphology (Fig. 4D,E). Although their main projections exited the anterior nerve root in a similar manner and also gave rise to longitudinal branches, these were shorter and less regular than the ones of Lox4-positive pRMVs (Fig. $4 D, E)$. Moreover, the branches of the nRMVs produced an extensive network of fine processes that was not found in the pRMVs. Further, one of the branches of the MG2 nRMVs was found to arborize over an unknown structure near the midline (Fig. 4D), resembling somewhat the major branch of the RPEs that innervates the male organ. The differences between the two types of RMVs became apparent at E9, but were most obvious at E12. These results are summarized in Figure 5.

We conclude that the RPEs of MG6, the nRMVs of MG2MG3, and the pRMVs of MG4, 5, 7, and 8 have three divergent axonal morphologies that correlate with differences in the expression of Lox4.

\section{Discussion}

\section{Possible roles of Lox 4 in neuronal differentiation}

During embryogenesis, the RPE's and the RPE homologs may be grouped according to their expression of Lox4. Lox4 is transiently expressed in the RPEs of MG6, it is continuously expressed in the pRMVs of MG4-MG5 and MG7-MG21, and it is never expressed in the nRMVs of MG1-MG3. These three different temporal patterns of expression within this series of segmentally homologous neurons correlate with the three distinct axonal morphologies of nRMVs, pRMVs, and RPEs. However, it should be noted that the nRMVs of MG2 and the RPEs of MG6, both of which do not express Lox4 when they are sending their processes to the periphery, share a morphological feature of their peripheral arbors: the presence of a process that reaches the midline and branches profusely. The pRMVs, which express Lox4 during the period of process outgrowth, never project branches to the midline. The distinct arborization patterns of nRMVs and pRMVs suggest that their peripheral targets are different not only from those of the RPEs but also from one another. The close correlation of Lox4 expression and different axonal morphologies (and perhaps targets) suggest that Lox4 


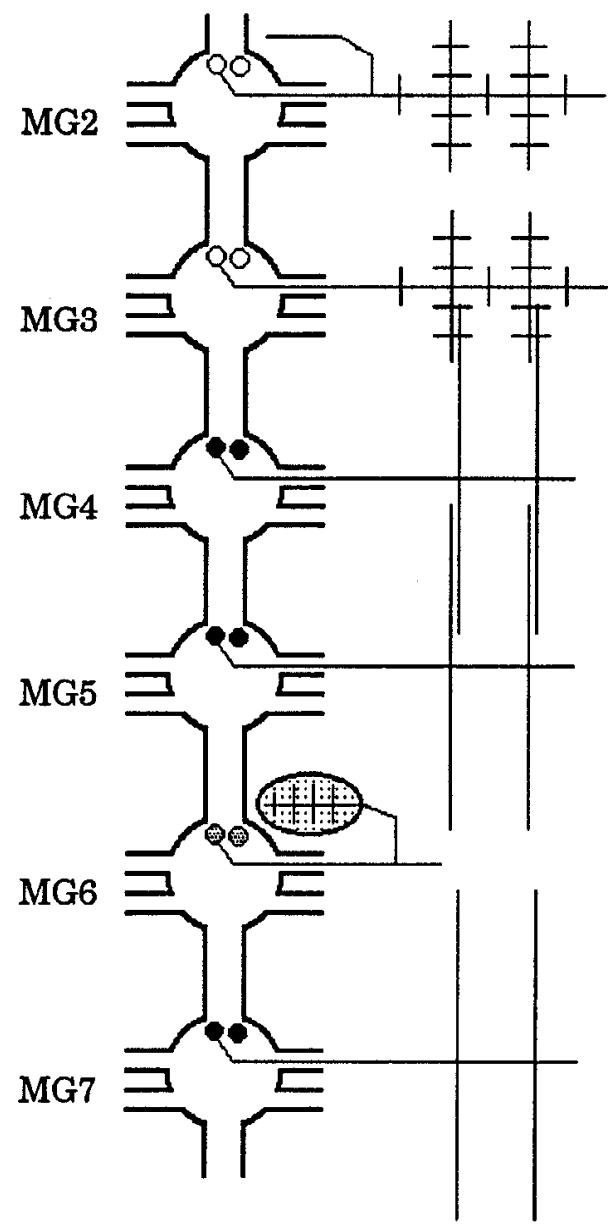

Figure 5. Lox4 expression and morphology of RPEs, nRMVs, and pRMVs. This schematic drawing summarizes the results presented in Figures 2-4. The Lox4-negative nRMVs are represented by open circles, the Lox4-positive pRMVs by solid circles, the transiently expressing RPEs by shaded circles, and the male organ by a shaded ellipse.

may determine the emergence of three distinct phenotypes within an initially homogeneous set of segmental homologs.

It is not known what mechanism generates the differential expression of Lox 4 in the RPEs. The fact that the Lox4 mRNA and protein disappear at about the same time suggests that Lox4 expression is regulated in these neurons at the transcriptional level. One possibility would be that other regulatory proteins present in the RPEs turn off Lox4 in a cell-autonomous fashion. An alternative possibility is that cell-cell interactions are involved. A potential influence is the male organ, whose presence is known to be required for the mature morphology of the RPEs (Baptista and Macagno, 1988) and the Retzius cells (reviewed in French and Kristan, 1994). However, removal of the male organ at early E8 did not change the time course of Lox4 expression in the RPEs and RMVs. This suggests that the male organ does not play a role in the downregulation of Lox4. It should be noted that its removal at E8 may not be early enough if induction occurs via long-range diffusible factors before this age.

The specification of neuronal fate by a homeobox gene has been observed in other systems. For example, the Drosophila segmentation genes $\mathrm{ftz}$ and $\mathrm{eve}$ are required to determine the morphology of identified motor neurons (Doe et al., 1988a,b). The downregulation of the Drosophila POU gene miti-mere is necessary for the daughter cells of a certain ganglion mother cell to assume different cell fates (Bhat and Schedl, 1994). In the embryonic CNS, the normal phenotype of the lineage of a certain specific neuroblast is controlled by $U b x$ in the first abdominal segment (A1), and by $a b d-A$ in A2-A7 (Prokop and Technau, 1994). $U b x$ and $a h d-A$ also specify some larval sensory organs (Heuer and Kaufman, 1992; Castelli-Gair et al., 1994). When the expression of grasshopper engrailed is inhibited in the unpaired median neuroblast lineage, extra neurons are generated instead of the midline glia (Condron et al., 1994). In C. elegans, lin-39 and mab-5 act combinatorially to determine neuronal identities (Clark et al., 1993; Salser et al., 1993), and unc-30 controls the differentiation of GABAergic neurons (Jin et al., 1994).

We propose that the presence and timing of Lox4 expression play an important role in establishing the identity of the members of the RPE-RMV series, allowing them to adopt three different fates. Because Lox 4 codes for a transcription factor, this could be accomplished by differentially regulating the expression of the structural genes or extracellular receptors that influence the shape and branching of the axons of these neurons. According to this model, if any of these neurons did not express Lox 4 by the end of gangliogenesis, they would assume the fate of the nRMVs, which would be the default phenotype for this particular cell type. However, in the continuous presence of Lox4 protein, the developmental pathway of these cells would be altered and they would adopt the PRMV fate instead. Finally, the downregulation of the Lox4 protein at the end of gangliogenesis would allow the RPEs to follow still another pathway of development.

\section{Origin of multiple Ubx/abd-A homologs in leeches}

The homeodomain of Lox4 can be classified as belonging to the Antp-class on the basis of its overall homology to Drosophila Antp, conservation of the recognition helix and presence of a YPWM motif. This type of Hox/HOM gene has been previously found in leeches (Wysocka-Diller et al., 1989; Shankland et al., 1991; Nardelli-Haefliger and Shankland, 1992; Aisemberg and Macagno, 1993), and in other organisms as diverse as cnidarians and vertebrates (reviewed in Kappen and Ruddle, 1993). Among the Hox/HOM genes, only the homologs of the fly genes labial $(l b)$, proboscipedia $(p b)$, Deformed $(D f d)$, and abdominal-B $(a b d-B)$ can be unequivocally identified in many different phyla and are likely to have been represented in a primitive Hox/HOM complex of a common ancestor of all metazoans. The remaining Hox/HOM genes [i.e., fly Sex combs reduced (Scr), fushi tarazu (ftz), Antp, Ubx, and $a b d-A$, and the vertebrate Hox genes of groups 6-8] are so similar within any given species that it is not possible to unambiguously identify their orthologs in distantly related organisms (reviewed in Krumlauf, 1994).

Contrary to this general finding, leech Lox2 (Wysocka-Diller et al., 1989; Nardelli-Haefliger and Shankland, 1992) and Lox4 can be identified as homologs of the insect $U b x$ and $a b d-A$ genes (Kornfeld et al., 1989, Karch et al., 1990), on the basis of sequence similarity and expression pattern. These four genes share a unique conserved motif, adjacent to the C-end of the homeodomain, that has not been found thus far in any phylum other than Arthropoda and Annelida. Within this motif, Lox2 and Lox4 are more similar to $U b x$ than any of these three genes to $a b d$ $A$, suggesting that insect $U b x$ is closer to the original sequence of a putative $U b x / a b d-A$-like gene in a common ancestor of both annelids and arthropods. In addition to these homologies, the 
primary embryonic domain of expression of these genes is similarly restricted to posterior segments. However, we cannot distinguish between Lox2 and Lox4 as the homolog of $U b x$ or $a b d-A$ on the basis of sequence homology and expression paltern. Lox2 and Lox4 are more similar to each other than either of these leech genes to $U b x$ or $a b d-A$, suggesting that the duplications giving rise to Lox $2 / L o x 4$ and $U b x / a b d-A$ occurred independently within the annelid and arthropod lineages.

It has been postulated that the duplication events leading to the array of trunk HOM genes (Scr, Antp, $U b x, a b d-A)$ present in modern insects took place before the divergence of insects and crustaceans from their last common ancestor (Averof and Akam, 1993). When these results and our data are considered together, they also imply that these duplications occurred before the divergence of annelids and arthropods. Surprisingly, we recently identified a new leech homeobox gene, Lox15, which shows extensive homology to Lox2 and Lox4 (our unpublished observations). The previously characterized genes Loxl (Aisemberg and Macagno, 1994) and Lox5 (Shankland et al., 1991) are also homologs of trunk HOM genes.

Such a large number of trunk HOM genes is somewhat unexpected, given the relative morphological simplicity of the leech. It is possible, however, that only in certain groups of animals these Hox/HOM genes acquired morphogenetic functions such as the specification of segmental identities. In this context, it is not surprising that in the leech Helobdella the expression of Lox 2 does not seem to be regulated by A-P positional information, but only by the birth order of the neuronal precursors (Nardelli-Haefliger et al., 1994). Since leeches do not subdivide their midbody regions to form specialized functional units like a thorax or an abdomen, the expression of numerous HOM genes may be primarily required in these animals to specify individual neuronal fates, rather than segment identities. The fact that Lox1, Lox2, Lox4 and Lox15 have their primary sites of expression in specific subsets of central neurons that are repeated within different but partially overlapping long A-P domains also supports this idea.

\section{References}

Aisemberg GO, Macagno ER (1994) Loxl, an Antennapedia-class homeobox gene, is expressed during leech gangliogenesis in both transient and stable central neurons. Dev Biol 161:455-465.

Aisemberg GO, Wysocka-Diller J, Wong VY, Macagno ER (1993) Antennapedia-class homeobox genes define diverse neuronal sets in the embryonic CNS of the leech. J Neurobiol 24:1423-1432.

Aisemberg GO, Wong VY, Macagno ER (1995) Genesis of segmental identity in the leech nervous system. In: The nervous systems of invertebrates: an evolutionary and comparative approach (Breidbach O, Kutsch W, eds), pp 77-87. Basel: Birkhaiiser.

Ausubel FM, Brent R, Kingston RE, Moore DD, Seidman JG, Smith JA, Struhl K, eds (1987) Current protocols in molecular biology. New York: Wiley.

Averof M, Akam M (1993) HOM/Hox genes of Artemia: implications for the origin of insect and crustacean body plans. Curr Biol 3:7378.

Baptista CA, Macagno ER (1988) Modulation of the pattern of axonal projections of a leech motor neuron by ablation or transplantation of its target. Neuton 1:949-962.

Becker T, Berliner AJ, Nitabach MN, Gan W-B, Macagno ER (1995) Target-induced neurogenesis in the leech CNS involves efferent projections to the target. Development 121:359-369.

Bhat KM, Schedl P (1994) The Drosophila miti-mere gene, a member of the POU family, is required for the specification of the RP2/sibling lineage during neurogenesis. Development 120:1483-1501.

Boncinelli E, Simeone A, Acampora D, Gulisano M (1993) Homeobox genes in the developing central nervous system. Ann Genet 36:30 37.
Bürglin T (1993) A comprehensive classification of homeobox genes. In: Guide to the homeobox genes (Duboule D, ed), pp 25-71. Oxford: Oxford UP.

Castelli-Gair J, Greig S, Micklem G, Akam M (1994) Dissecting the temporal requirements for homeotic gene function. Development 120 : 1983-1995.

Clark S, Chisholm A, Horvitz HR (1993) Control of cell fates in the central body region of $C$. elegans by the homeobox gene lin-39. Cell $74: 43-55$.

Condron BG, Patel NH, Zinn K (1994) engrailed controls glial/neuronal cell fate decisions at the midline of the central nervous system. Neuron 13:541-554.

Doe CQ, Scott MP (1988) Segmentation and homeotic gene function in the developing nervous system of Drosophila. Trends Neurosci 11:101-106.

Doe CQ, Hiromi Y, Gehring WJ, Goodman CS (1988a) Expression and function of the segmentation gene fushi tarazu during Drosophila neurogenesis. Science 239:170-175.

Doe CQ, Smouse D, Goodman CS (1988b) Control of neuronal fate by the Drosophila segmentation gene even-skipped. Nature 333:376378.

Fernández J, Stent G (1982) Embryonic development of the hirudinid leech Hirudo medicinalis: structure, development and segmentation of the germinal plat. J Embryol Exp Morphol 72:71-96.

French KA, Kristan WB (1994) Cell-cell interactions that modulate neuronal development in the leech. J Neurobiol 25:640-651.

Gan W-B, Macagno ER (1995) Interactions between segmental homologues and between isoneuronal branches guide the formation of sensory terminal fields. J Neurosci 15:3243-3253.

Gao W-Q, Macagno ER (1987a) Extension and retraction of axonal projections by some developing neurons in the leech depends upon the existence of neighboring homologues. I. The HA cells. J Neurobiol 18:43-59.

Gao W-Q, Macagno ER (1987b) Extension and retraction of axonal projections by some developing neurons in the leech depends upon the existence of neighboring homologues. II. The AP and AE neurons. J Neurobiol 18:295-313.

Glover JC, Mason A (1986) Morphogenesis of an identified leech neuron: segmental specification of axonal outgrowth. Dev Biol 115:256260.

Heuer J, Kaufman T (1992) Homeotic genes have specific functional roles in the establishment of the Drosophila embryonic peripheral nervous system. Development 115:35-47.

Jellies J, Loer CM, Kristan WB Jr (1987) Morphological changes in leech Retzius neurons after target contact during embryogenesis. J Neurosci 7:2618-2629.

Jellies J, Kopp DM, Bledsoe JW (1992) Development of segment- and target-related neuronal identity in the medicinal leech. J Exp Biol 170:71-92.

Jin Y, Hoskins R, Horvitz HR (1994) Control of type-D GABAergic neuron differentiation by $C$. elegans Unc-30 homeodomain protein. Nature 372:780-783.

Kappen C, Ruddle F (1993) Evolution of a regulatory gene family: HOM/HOX genes. Curr Opin Genet Dev 3:931-938.

Karch F, Bender W, Weiffenbach B (1990) abdA expression in Drosophila embryos. Genes Dev 4:1573-1587.

Kessel M, Gruss P (1990) Murine developmental control genes. Science 249:374-379.

Kornfeld K, Saint RB, Beachy PA, Harte PJ, Peattie DA, Hogness DS (1989) Structure and expression of a family of Ultrabithorax mRNAs generated by alternative splicing and polyadenylation in Drosophila. Genes Dev 3:243-258.

Krumlauf R (1994) Hox genes in vertebrate development. Cell 78:191201.

Lipman DJ, Altschul SF, Kececioglu JD (1989) A tool for multiple sequence alignment. Proc Natl Acad Sci USA 86:4412-4415.

Macagno ER (1980) Number and distribution of neurons in leech segmental ganglia. J Neurosci 7:1911-1918.

McGinnis W, Krumlauf R (1992) Homeobox and axial patterning. Cell 68:283-302.

Nardelli-Haefliger D, Shankland M (1992) Lox2, a putative leech segment identity gene, is expressed in the same segmental domain in different stem cell lineages. Development 116:697-710.

Nardelli-Haefliger D, Bruce AEE, Shankland M (1994) An axial domain of HOM/Hox gene expression is formed by morphogenetic 
alignment of independently specified cell lineages in the leech $\mathrm{He}$ lobdella. Development 120:1839-1849.

Prokop A. Technau GM (1994) Early tagma-specific commitment of Drosophila CNS progenitor NB1-1. Development 120:2567-2578.

Salser SJ, Loer CM, Kenyon C (1993) Multiple HOM-C gene interactions specify cell fates in the nematode central nervous system. Genes Dev 7:1714-1724.

Schncuwly, S, Kuroiwa A, Baumgrtner P, Gehring W (1986) Structural organization and sequence of the homeotic gene Antennapedia of Drosophila. EMBO J 5:733-739.

Scott MP (1992) Vertebrate homeobox gene nomenclature. Cell 71: $551-553$.

Shankland M, Martindale MQ, Nardelli-Haefliger D, Baxter E, Price DJ (1991) Origin of segmental identity in the development of the leech nervous system. Development [Suppl] 2:29-38.
Smith DB, Johnson KS (1988) Single-step purification of polypeptides expressed in Escherichia coli as fusion with glutathione S-transferase. Gene 67:37-40.

Stewart RR, Gao W-Q, Macagno ER (1991) Segmental differentiation in the leech central nervous system: proposed segmental homologs of the heart accessory neurons. J Comp Neurol 313:431-440.

Tear G, Akam M, Martinez-Arias A (1990) Isolation of an abdominal-A gene from the locust Schistocerca gregaria and its expression during early embryogenesis. Development 110:915-925.

Wysocka-Diller JW, Aisemberg GO, Baumgarten M, Levine M, Macagno ER (1989) Characterization of a homologue of bithorax-complex genes in the leech Hirudo medicinalis. Nature 341:760-763.

Zipser B (1979) Identifiable meurons controlling penile eversion in the leech. J Neurophysiol 42:455-464. 